\title{
Virtualidade e equivocidade do ser nos xamanismos ameríndios
}

[ Virtuality and equivocity of being in Amerindian shamanisms

\section{Pedro de Niemeyer Cesarino ${ }^{\mathrm{I}}$}

RESUMO - O presente artigo pretende explorar alguns aspectos dos problemas da tradução e da variação ontológica nos estudos dos xamanismos ameríndios, em especial no que se refere à maneira pela qual têm sido pensadas as conexões e limites do humano pela escrita etnográfica. Para tanto, o artigo revisa alguns dos pressupostos relacionados ao uso da noção de ontologia na teoria antropológica, tendo em vista discutir os dilemas relacionados à tradução das cópulas predicativas e suas consequências para a compreensão dos regimes xamanísticos de conhecimento, assentado em configurações virtuais. P PALAVRAS-CHAVE - Virtualidade; equívoco; ontologia; tradução; xamanismo. - ABSTRACT - This article discusses the relationships between ontological variation, translation and the study of Amerindian shamanism and its conceptions of human extensions and connections. Revising some aspects of the anthropological use of the notion of ontology, the article explores some ethnographic translations of copular verbs and its consequences for the undestanding of shamanistic virtual regimes of knowledge. KEYWORDS - Virtual; equivocity; ontology, translation, shamanism.

Recebido em I4 de novembro de 2017

Aprovado em 3 I de janeiro de 2018

CESARINO, Pedro de Niemeyer. Virtualidade e equivocidade do ser nos xamanismos ameríndios. Revista do Instituto de Estudos Brasileiros, Brasil, n. 69, p. 267-288, abr. 2018.

DOI: http://dx.doi.org/Io.II606/issn.23I6-90IX.voi69p267-288

I Universidade de São Paulo (USP, São Paulo, SP, Brasil). 
A tão discutida virada ontológica tem como uma de suas principais tarefas a produção de conceitos para lidar com a diversidade de problemas colocados pela etnografia ${ }^{2}$. Essa tarefa, relacionada ao estabelecimento de conexões parciais ${ }^{3}$ entre distintos regimes de conhecimento, está necessariamente atrelada ao problema da tradução, cujas consequências para a teoria antropológica são decisivas. Afinal, é dessa aliança que depende o projeto de multiplicação de conceitos, capaz de oferecer mais elementos para aquilo que Mauro Almeida ${ }^{4}$ reconheceu como um campo de luta relacionado à variação dos modos de conhecer. A aliança entre a tradução e a proliferação conceitual, entretanto, é realizada de maneira menos sistemática e rigorosa do que mereceria, fazendo com que a especulação etnográfica frequentemente desperdice seu potencial imaginativo. Por causa disso, é comum que matrizes ontológicas modernas passem a ser consideradas pelas alheias, já que muitas vezes estão inscritas em uma linguagem analítica ${ }^{5}$ nem sempre atenta ao necessário esforço autorreflexivo, aliás propagado por alguns dos expoentes do "método ontológico".

Pretendo aqui explorar o assunto através de uma reflexão sobre o tratamento etnográfico da definição do humano, de suas relações de limite e de vizinhança. Certamente vasto, o problema será desenvolvido a partir do exame pontual de determinadas soluções que costumam ser dadas para as supostas relações de fusão, sobreposição ou identificação entre humano e não humano (entre pessoas, animais e montanhas, por exemplo). Essas relações tendem a ser escritas na etnografia via o uso recorrente da cópula ontológica, que costuma ser ativada para estabelecer uma

2 Cf.: VIVEIROS DE CASTRO, Eduardo. A inconstância da alma selvagem. São Paulo: Cosac Naify, 2002; HOLBRAAD, Martin; PEDERSEN, Morten Axel. The ontological turn - an anthropological exposition. Cambridge: Cambridge University Press, 20I7. Todas as traduções de citações em língua estrangeira são minhas.

3 STRATHERN, Marilyn. Partial connections. Oxford: Altamira Press, 2005.

4 ALMEIDA, Mauro William Barbosa de. Caipora e outros conflitos ontológicos. R@u v. 5, n. I, 20I4, p. 7-28. p. 24

5 STRATHERN, Marilyn. The gender of the gift. Berkeley: The University of California Press, I988.

6 HOLBRAAD, Martin; PEDERSEN, Morten Axel, op. cit. 
espécie de alternativa ao problema moderno da representação. Uma reflexão sobre os entraves linguísticos e conceituais envolvidos em tais soluções é fundamental para a compreensão do que se entende por conhecimento nos xamanismos ameríndios. Quais são as formas de relação entre humano e não humano postuladas por tais xamanismos? Quais relações de conhecimento surgem daí? Derivariam elas de um sujeito autocentrado ou de outras configurações do real, para as quais a noção de virtualidade desempenharia um papel fundamental ao redistribuir as formas de identificação e de produção do saber?

\section{ONTOLOGIA E EQUIVOCIDADE DO SER}

Para desenvolver as questões acima colocadas, cabe recuperar alguns aspectos importantes dos debates recentes sobre a relação entre antropologia e ontologia, em especial aqueles relacionados à equivocidade do ser. Muito embora não seja ponto pacífico, a remodelação antropológica do conceito de ontologia o tem transformado em algo não necessariamente compatível com a sua invenção filosófica original, tributária das clássicas e modernas metafísicas do Ser. O tratamento antropológico do conceito é mais próximo de uma proliferação intensiva de multiplicidades, justamente aquela pensada por Deleuze e Guattari ${ }^{7}$ nos Mil platôs para dar conta de fenômenos que escapam ao solipsismo e monismo ocidentais. Com isso, o que se pretende é radicalizar os processos de conexão, comparação e tradução a fim de neutralizar a projeção de pressupostos metafísicos modernos sobre outrem ${ }^{8}$. Trata-se, portanto, de uma tarefa bastante distinta da "replicação de divisões tipológicas" ou de uma projeção descontrolada do problema do Ser sobre outrem, como alertou recentemente Severi ${ }^{\mathrm{IO}}$ em suas críticas ao uso da noção de ontologia na antropologia.

Quando se fala em ontologias ameríndias ou, antes, quando são levantadas questões ontológicas postas pelos regimes ameríndios de conhecimento (se vale

7 DELEUZE, Gilles; GUATTARI, Félix. Mille plateaux. Paris: Les Éditions de Minuit, I980.

8 Para compreender melhor o ponto, tomemos como exemplo o caso da tradução fundamental de León Cadogan do Ayvu Rapyta, um ciclo de narrativas míticas dos Guarani Mbya. Cadogan toma o demiurgo da ontologia guarani, Ñamandu, por uma tradução perfeita do conceito de "absoluto" e, dessa maneira, transforma a cena inicial do Ayvu rapyta em uma espécie de gênese produzida por um "deus criador". CADOGAN, León. (I946). Ayvu rapyta - textos míticos de los Mbyá-Guaraní del Guairá. Asunción: Ceaduc-Cepag, I997, p. 29. Pierre Clastres (1974), não por acaso, revisará a tradução de Cadogan e proporá outras soluções para a terminologia excessivamente greco-cristã empregada pelo autor. CLASTRES, Pierre. Le grand parler. Paris: Seuil, I974. Essas soluções apontam mais para a natureza recursiva dos agentes primeiros ameríndios, que não se compreendem através dos contornos de uma divindade individualizada autora de efeitos sobre o mundo. Ver: CESARINO, Pedro de Niemeyer. A voz falível - ensaio sobre as formações ameríndias de mundos. Literatura e Sociedade, n. I9, 2014, p. 76-99.

9 HANKS, William; SEVERI, Carlo. Translating worlds. The epistemological space of translation. Hau - Journal of Ethnographic Theory, v. 4, n. 2, 20I4, p. I-I6. p. 9.

IO SEVERI, Carlo. Transmutating beings - a proposal for an anthropology of thought. Hau, v. 4, n. 2, 20I4, p. 4I-7I. p. 6I. 
tomar de empréstimo a sugestão metodológica recentemente feita por Holbraad e Pedersen $^{\mathrm{II}}$ ), não se está exatamente projetando “ontologias pseudoparmenidianas” na Amazônia, ou seja, imaginando que tais formas de conhecimento assentariam sobre "sistemas de pensamento coerentes, 'únicos, imóveis e imutáveis' como o conceito parmenidiano de Ser" ${ }^{\text {I2 }}$. Ora, o uso da noção de ontologia em uma reflexão tradutória não implica necessariamente a ativação de tal imagem genérica de uma metafísica pré-socrática que, diga-se de passagem, tem sido revisada. Não por acaso, ao escrever sobre as diversas camadas de interpretação do Poema de Parmênides impostas pela história da filosofia, Barbara Cassin ${ }^{\mathrm{I} 3}$ enfrentava um dos pilares ontológicos do Ocidente: a tarefa de revisar a própria constituição da narrativa do Ser via as diversas invenções do Poema por seus tradutores e comentadores modernos e antigos. Trata-se de uma invenção responsável pela produção de um fait de langue que estabelece o suposto privilégio metafísico e filosófico dos gregos, a despeito de diversas das peculiaridades gramaticais do texto pré-socrático.

Uma reflexão distinta e ainda mais recente sobre esse mesmo pressuposto do Ser - mas, dessa vez, diretamente voltada para o seu engajamento com uma antropologia comparativa - foi realizada pelo filósofo Patrice Maniglier. Para ele, a questão do ser

[...] não está sobre a condição da negação radical do ser e do nada, mas sobre a condição de uma irrupção imprevista da equivocidade da palavra "ser" em nossas práticas ordinárias. Não a negação, portanto, mas a multiplicidade. [...] a questão do ser surge quando se percebe que a palavra "ser" poderia ser uma palavra radicalmente equívoca ${ }^{\mathrm{I}}$.

Ecoando as reflexões de Viveiros de Castro $^{15}$ sobre o problema da tradução equívoca, Maniglier também aponta para outras potencialidades do ser que não necessariamente coincidem com a metafísica ocidental do Ser. Tal estratégia implica um compromisso político com a multiplicidade ontológica. Para Maniglier, a equivocidade do ser supõe "não tanto uma visão do todo, mas sim o rasgar de um contínuo aparente"ㄷ․ Essa incisão é o que poderia produzir uma compreensão melhor do que há de comensurável entre distintas práticas de conhecimento, ou seja, o exercício da variação.

Mas, ainda assim, resta a pergunta: como seria possível pensar essa variação ontológica para a compreensão dos regimes ameríndios de conhecimento? Em um de seus estudos dedicados ao contraste entre os antigos pensamentos chineses

II HOLBRAAD, Martin; PEDERSEN, Morten Axel, op. cit.

I2 SEVERI, Carlo, 20I4, op. cit., p. 6I.

I3 CASSIN, Barbara. Parménide - sur la nature ou sur l'étant. La langue de l'être. Paris: Seuil, I998.

I4 MANIGLIER, Patrice. Manifesto para um comparatismo superior em filosofia. Tradução Richer de Souza e Melissa Mora Mello. Veritas - Revista de Filosofia da PUCRS, v. 58, n. 2, 20I3, p. 227-27I. p. 242. Disponível em: 〈revistaseletronicas.pucrs.br/ojs/index.php/veritas/article/view/I6645/IO9I4〉. Acesso em: 22 jan. 2018.

I5 VIVEIROS DE CASTRO, Eduardo. Perspectival anthropology and the method of controlled equivocation.

Tipití, v. 2, n. I, 2004, p. 3-23.

I6 MANIGLIER, Patrice, op. cit., p. 242. 
e gregos, G. E. R. Lloyd argumentou em favor da multiplicidade ontológica, por ele compreendida como uma consequência direta das diferenças de "estilos de investigação, eles próprios constituídos por distintas perspectivas e preocupações" Para Lloyd, "as diferenças de perspectiva não excluem a possibilidade de pontos de contato entre aquilo que existe para que as perspectivas se estabeleçam" ${ }^{18}$, assim garantindo a existência de um espaço, igualmente comum, no qual se desenvolvem disputas e controvérsias. É de fato interessante que as especulações ameríndias não sejam sistemáticas assim como os sistemas filosóficos modernos, o que não necessariamente implica a inexistência de alguma coerência explícita ou implícita, como se suas formas de pensamento se diluíssem sempre e necessariamente em "práticas específicas, em sistemas de relação e em gêneros de discurso", como sugeriu recentemente Severi ${ }^{19}$. O autor, de toda forma, tem razão ao se preocupar com uma potencial projeção indevida das metafísicas do Ser sobre mundos outros, assim como também Holbraad e Pedersen ${ }^{20}$ estão corretos ao expressarem suas ressalvas sobre a recente proposição de ontologias alternativas às custas de materiais etnográficos não ocidentais (caso dos trabalhos recentes de Eduardo Kohn e de Tim Ingold, entre outros).

As ressalvas, entretanto, apenas anunciam os dilemas envolvidos na compreensão das estratégias alheias para refletir sobre distintos modos de existência. Quais especificidades linguísticas estariam envolvidas nas questões ontológicas pertinentes para configurações xamanísticas como as ameríndias? Se é verdade que a relação entre língua e pensamento não pode ser concebida de maneira automática e determinista ${ }^{2 \mathrm{I}}$, tal aproximação, entretanto, não poderá jamais ser descartada por completo. A relação, por um lado, condiciona muitos dos pontos cegos e acertos tradutórios produzidos pela escrita etnográfica, além de oferecer pistas importantes sobre outros critérios de pensamento tais como os ameríndios. São exatamente esses pontos cegos que costumam obscurecer a compreensão de tais critérios; não é raro, ademais, que eles estejam diretamente associados a vícios de linguagem e de tradução

I7 LLOYD, G. E. R. The ambitions of curiosity. Cambridge: Cambridge University Press, 2002, p. 9I.

I8 Ibidem.

I9 SEVERI, Carlo, 20I4, op. cit., p. 6I. Mostrei em outro trabalho (CESARINO, Pedro de Niemeyer. Oniska poética do xamanismo na Amazônia. São Paulo: Perspectiva/Fapesp, 20II, p. 83-85, 206-226, 287-292) como os xamãs marubo produzem conversas especulativas complexas, coerentes e constantes sobre os processos de formação do que existe, bem como sobre a própria condição humana, empregando critérios de pensamento não muito distintos daqueles presentes entre os Guarani-Mbyá (CADOGAN, León, op. cit.) e entre os Yanomami (ALBERT, Bruce; KOPENAWA, Davi. La chute du ciel. Paris, Plon, 20Io). Trata-se, é verdade, daquelas sociedades nas quais parece se estabelecer um processo de transmissão de conhecimentos rituais e especiais, cujas produções verbais e intelectuais não foram intencionalmente estudadas por Lévi-Strauss nas Mitológicas. Mas isso não quer dizer que, em outras sociedades nas quais não se nota a existência de tradições exegéticas e especulativas consolidadas em torno de expressões verbais, inexistam pressupostos menos explícitos (ou ao menos verbalmente menos estruturados) sobre o que existe. A tarefa (a ser aprofundada em outro trabalho) estaria, então, em compreender as condições de sua coerência.

20 HOLBRAAD, Martin; PEDERSEN, Morten Axel, op. cit., p. 55 ss.

$2 I$

Cf. HANKS, William; SEVERI, Carlo, op. cit. 
que remontam a uma espécie de fantasmagoria do Ser impregnada no discurso etnográfico. A reflexão sobre o processo e o conceito de tradução não pode, portanto, ser separada do problema ontológico ${ }^{22}$. Vejamos algumas consequências de tal separação em exemplos extraídos de produções recentes da etnologia americanista, dedicados exatamente às fronteiras do humano e suas formas de relação.

\section{O PROBLEMA da CóPUla ONTOLÓGICA}

Em sua análise dos dados da etnografia de Jean-Michel Beaudet sobre a música dos Wayãpi (falantes de tupi-guarani do Amapá), Carlo Severi tratava da relação entre música e os “'donos' não humanos da música”: a música, concebida como um chamado composto de um fragmento melódico, é então por ele descrita como "a encarnação musical de seu nome"23. "Quando a música é ritualmente endereçada a um espírito invisível", segue o autor, "sua relação entre o motivo performado e o ser visado (e imitado) se torna mais forte. Neste caso, o espírito invisível não é mais 'apenas imitado' pela música. Ele 'é’ a música”"24. Em um estudo recente sobre os petróglifos do Alto Rio Negro, Stephen Hugh-Jones considera que uma parte significativa de tais marcas poderia ser concebida como um conjunto de representações dos instrumentos do Jurupari. O ponto, na realidade, é nuançado pelo autor da seguinte maneira:

[...] mas aos olhos dos indígenas, estes não são representações, e sim a coisa real. Os petróglifos são Jurupari em outra forma. É por isso que as pessoas devem desviar o olhar deles, e não encará-los. Nessa mesma lógica, para os Tukano, as anacondas ancestrais não chegaram meramente pelos rios; os rios são os ancestrais e foram criados à medida em que as cobras se moviam ${ }^{25}$.

Nas duas análises, dirigidas a casos etnográficos distintos, vemos Severi e Hugh-Jones se valerem da cópula ontológica como forma de explicação de relações que, do ponto de vista moderno, seriam consideradas como contraintuitivas ou paradoxais. Um recurso similar pode ser encontrado, desta vez, na etnografia de Marisol de la Cadena sobre os quéchua da região de Cuzco (Peru), dedicada a explorar as formas de relação entre pessoas (runakuna, os falantes monolíngues de quéchua) e seres-terra (earth beings, ou tirakuna, "um nome composto formado

22 Tal omissão aparece de maneira surpreendente na análise recente de Holbraad e Pedersen (op. cit.) sobre a virada ontológica, o que compromete de maneira significativa o projeto metodológico ali proposto pelos autores.

23 SEVERI, Carlo, 20I4, op. cit., p. 57.

24 Ibidem (grifos meus).

25 HUGH-JONES, Stephen. Escrita nas pedras, escrita no papel. In: FAUSTO, C.; SEVERI, C. Palavras em imagens

- escritas, corpos e memórias. Marseille: Open Edition Press, 20I5, p. 57-85. p. 7I (grifos meus) 
por tierra, o termo espanhol para 'terra', e pluralizado pelo sufixo quéchua kuna"26. Em seu livro, a autora pretende mostrar como, apesar da convivência histórica entre peruanos limeños e falantes de quéchua do altiplano andino, as "formas de conhecer, de praticar e de fazer mundos distintos - os nossos worldings ou modos de fazer mundos - produziram circuitos entre si e partilharam práticas por séculos, ainda que não tenham se fundido. "Neste circuito", segue a autora, "algumas práticas evidentemente se subordinaram, ainda que não tenham desaparecido sob aquelas que se tornaram dominantes, e nem sequer se fundiram em um único e simples híbrido" ${ }^{27}$. Um dos aspectos explorados pela etnógrafa para evidenciar tais diferenças entre regimes ontológicos e suas respectivas formas de conhecimento é o das estratégias de nominação estabelecidas entre os runakuna (entre eles, um de seus interlocutores preferenciais, o xamã Nazario Turpo) e os tirakuna, tais como o imponente ser-montanha Ausangate. Vejamos como a autora concebe a suposta peculiaridade de tal estratégia:

Para os runakuna (Nazario incluído), tirakuna são os seus nomes. Mais ainda, não existe separação entre a palavra Ausangate e o ser-terra Ausangate; nenhum "significado" intermedeia o ser e seu nome. [...] seres-terra não apenas têm nomes; eles são quando mencionados, quando convocados ${ }^{28}$.

Nessa passagem, Marisol de la Cadena reflete não apenas sobre o que parece ser uma característica geral da nominação ritual nos Andes mas, mais especificamente, sobre a seguinte explicação oferecida por Nazario: "Você deverá soprá-las (sobre as folhas de coca) e nomeá-los (os seres-terra). Não é por acaso que dizemos Ausangate, eles são esses nomes... (Phukurikunki sutinmanta, manan yanqa Ausangatellachu nispa, sutiyoq kaman kashan nispa...)”². É interessante notar a constância do uso de um verbo de cópula que estabelece uma atribuição ou, a rigor, uma identidade forte entre dois elementos postos em relação. Uma busca por outras etnografias certamente confirmaria o ponto, pois, evidentemente, este é um recurso previsto em línguas indo-europeias tais como as utilizadas pela antropologia. Não conheço a gramática quéchua, wayana, wayãpi ou tukano para dizer se as funções de cópula em tais línguas efetivamente correspondem a esse transporte, quase que imediato, que se realiza nas tentativas etnográficas de especular sobre outras formas de constituição de vínculos. Tampouco me parece aqui necessário esmiuçar as gramáticas de tais línguas para delas extrair uma conclusão que seria óbvia: de que a eventual presença da cópula gramatical em línguas ameríndias não implica na mesma metafísica do Ser associado ao problema da predicação nas línguas indo-europeias. Trata-se, a rigor, de um problema antigo. Mesmo que seja aparentemente evidente, ele pertence ao nosso vocabulário analítico, alastrado pelos mais diversos estudos que se dedicam

26 LA CADENA, Marisol de. Earth beings - ecologies of practice across Andean worlds. Durham \& London:

Duke University Press, 20I5, p. xxiii.

27 Ibidem, p. 4 .

28 Ibidem, p. 25

29 Ibidem, p. 24 (o primeiro grifo é meu). 
a refletir sobre formas de conhecimento e de produção de vínculos não modernas, em princípio alheias ao problema da representação e da interposição metafórica entre dois polos de uma relação.

Para que o ponto se torne mais claro, vale recorrer a um exemplo proveniente de outra área de estudos: o clássico trabalho de David Freedberg sobre a agência das imagens, The power of images. Ao analisar a relação estabelecida pelos fiéis com determinada imagem figurativa (a Madona de Rocamadour, em Quercy, adorada desde os tempos medievais), Freedberg diz que tal processo de animação se torna possível porque "o signo se transformou na incorporação viva daquilo que significa" 30 . Para o autor, é a crença que inclina o observador a postular a presença da Virgem:

[...] não se pode acreditar que a Virgem esteja na figura - ou é a figura - a não ser que se acredite na Virgem. Assim, ao desejar a sua presença e sua existência, somos levados a nos concentrar na imagem, e aquilo que nela está representado se torna novamente presente. Ela é, de maneira muito literal, reapresentada. A passagem da representação para a apresentação é crucial para que a Virgem deixe de ser vista como um sinal [token] e passe a ser vista enquanto tal ${ }^{3 \mathrm{I}}$.

Fusão de imagem e de protótipo ${ }^{32}$, bem como de significante e de significado ${ }^{33}$, são então as operações responsáveis pela produção de eficácia das imagens. Afinal, também os Nupe da Nigéria, em seus rituais iniciáticos de máscaras, poderiam supostamente ser pensados da mesma maneira: "uma vez que o performador está dentro da máscara, ele se torna inseparável da coisa que ele 'representa': ele é o ndakó gboyá [o Avô ou Ancestral Gboyá]"34. A cópula ontológica, dessa maneira, parece descrever de maneira muito genérica e pouco objetiva as estratégias não modernas de produção de vínculos, bem como de supostas fusões inexplicáveis pela separação desencantada entre material e imaterial, interior e exterior, humano e não humano, e assim por diante. Não é por acaso que as pedras animadas (lithoi empsychoi) da Grécia arcaica supostamente se comportariam da mesma maneira. Algumas delas eram inclusive portadoras de inscrições que revelavam seus nomes: "Sou Terpon, servo da Deusa Afrodite", dizia uma delas. Sobre as pedras animadas, Freedberg produz a seguinte explicação circular: "a pedra é encontrada, passa a ser designada como sobrenatural e, portanto, se torna sobrenatural; daí em diante - como demonstra de maneira bastante clara o uso do pronome de primeira pessoa - ela se torna animada”35.

Dos Nupe da Nigéria, passando pelas figurações cristãs da Europa ocidental, bem como pelos Andes e pela Amazônia, uma estranha coincidência se revela: a mesma

30 FREEDBERG, David. The power of images. Chicago \& Londres: The University of Chicago Press, I989, p. 28.

3I Ibidem.

32 Ibidem, p. 30.

33 Ibidem, p. 32

34 NADEL apud FREEDBERG, David, op. cit.

35 FREEDBERG, David, op. cit., p. 67. 
forma de predicação existencial, que poderia servir, como no caso de Freedberg, para fundamentar uma espécie difusa de animismo pré ou não moderno, caracterizado pelo mecanismo subjetivo da crença e pela fusão daquilo que a metafísica da representação decidiu separar. A explicação, assim, é ativada de maneira automática toda vez que a análise se confronta com um caso limite, que desafia a sua capacidade de imaginação etnográfica. Além do mais, quando a análise se fia à noção de crença ou à mobilização de critérios de atribuição de verdade, ela também termina por reduzir os dilemas ontológicos alheios a uma questão psicológica ou subjetiva. É o que bem apontou Viveiros de Castro $^{36}$ ao alertar que as metafísicas outras não são uma mera questão de opinião ou de proposições linguísticas.

Essas posições, é certo, não estão distribuídas da mesma maneira entre os autores acima citados, dos quais apenas Severi e Freedberg aderem com mais constância aos recursos cognitivos e subjetivos tais como os envolvidos na noção de crença. Não se trata aqui de desvalidar etnografias, todas elas competentes, com base em análises linguísticas, que efetivamente não detêm o monopólio da validação do conhecimento etnográfico. Trata-se, isto sim, de atentar para determinado vício da linguagem analítica que transforma a capacidade de levantar questões ontológicas pela etnografia em uma petição de princípio desprovida de reflexividade. Por vezes, entretanto, o uso da cópula não impede necessariamente que tais questões sejam desenvolvidas de maneira mais interessante, terminando por produzir uma perturbação tradutória na teoria etnográfica. É o caso dos estudos de Marilyn Strathern sobre a Melanésia, como vemos na seguinte passagem de Partial connections: "não há diferença entre uma sequência de conchas e a matrilinhagem, entre um homem e um poste de bambu, entre um inhame e um espírito. Um 'é' o outro, na medida em que evocam de maneira equivalente a percepção de relações" ${ }^{37}$. Não fosse o complemento da última frase acima destacado, a interpretação da autora recairia nos mesmos vícios dos demais autores. Na falta de outro recurso gramatical, Strathern parece usar a cópula predicativa para evidenciar o peculiar estatuto da estética melanésia, cujo objetivo não é produzir uma fusão indistinta entre humano e não humano, mas sim evidenciar o resultado de relações acumuladas pelo gênero e pelas relações de dádiva.

De toda forma, a ênfase na cópula ontológica permanece constante e indica algo relevante: não exatamente a falta de embasamento linguístico (embora fundamental, não é este o conhecimento indispensável para a produção de teorias etnográficas), mas sim de desconfiança tradutória de muitos dos estudos que se prestam, justamente, a refletir sobre os regimes de conhecimento alheios ao problema

36 VIVEIROS DE CASTRO, Eduardo. O nativo relativo. Mana, v. 8, n. I, 2002, p. II3-I48. p. I30.

37 STRATHERN, Marilyn, 2005, op. cit., p. II8 (grifos meus). 
moderno da representação ${ }^{38}$. Do contrário, a mesma fórmula retórica ("X não é uma representação de Y; X é Y") não seria sacada do bolso exatamente nos momentos em que se trata de refletir sobre outros modos de produção de vínculo e suas vastas consequências políticas, sociológicas, epistemológicas e ontológicas. Mas poderia ser de outra forma? Poderíamos, mais ainda, escrever de outra maneira?

Talvez este seja apenas um detalhe pouco relevante. Seja como for, ele impede a imaginação etnográfica de produzir especulações sobre o "ser" como uma palavra equívoca, como queria Maniglier, e nos remete novamente a certa univocidade do ser, capaz de fundir sujeito e predicado em uma só presença, avessa por princípio aos dilemas da representação. Tudo se passa, assim, como se essa metafísica da presença pudesse ser aplicada a toda e qualquer forma não moderna de vínculo entre humano e não humano. Mas e se houver outros critérios de mediação? E se muitos dos sistemas gramaticais com os quais lidamos não se vincularem a essa metafísica e forem capazes de produzir outras equivocidades? Se a tentativa de extrair de tais sistemas gramaticais propriedades especulativas é arriscada, mas não impossível, não deixa de ser patente a projeção das propriedades ontológicas provenientes de nossos critérios linguísticos sobre os de outrem.

Como bem sabemos, esses critérios são herdeiros diretos de uma "situação linguística" específica (entre outras tantas possíveis) que tornou o ser, por sua função lógica, uma "noção objetivável”’’, passível de gerar todo aquele edifício ontológico que encontra na Metafísica de Aristóteles um de seus pilares fundadores. Essa "vocação filosófica" é, assim, uma entre outras consequências desencadeadas pela variedade de empregos de "ser" nas línguas indo-europeias; algo que, esclarece Benveniste, não é de modo algum universal ou mesmo necessário $4^{\circ}$. Aliás, é bem essa a desconfiança do célebre linguista com relação à comparação com o ewe, uma língua falada no Togo, para a qual cinco verbos fariam as vezes do que entendemos como ser. É o caso do verbo le, que conjuga uma determinação existencial a uma espacial e outra temporal. Benveniste termina por concluir o seguinte: "não saberíamos dizer que

38 Uma atenção aos usos de línguas indo-europeias como o português por indígenas (no Brasil, por exemplo), muito frequentemente feito através do mesmo recurso à cópula predicativa, renderia discussões interessantes que não posso conduzir aqui. Seria para tanto necessário, em primeiro lugar, não subestimar a capacidade de subversão especulativa inscrita na criatividade linguística indígena, cuja reinvenção do português é de tal forma complexa que frequentemente indica um rendimento conceitual alternativo. Ao cotejar discursos transcritos em português com traduções diretas das línguas nativas, a fim de refletir sobre os dilemas conceituais (e por vezes eminentemente poéticos) derivados de tal transporte tradutório, tal empresa poderia oferecer pistas importantes para uma compreensão descolonizada da adoção de uma segunda língua (a metropolitana) por segmentos sociais frequentemente postos em situação de dominação crônica.

39 BENVENISTE, Émile. Problemas de linguística geral I. Campinas: Pontes/Editora da Unicamp, I995, p. 77.

40 Ibidem, p. 79. 
lugar ocupa o 'ser' na metafísica ewe, mas a priori a noção deve articular-se de maneira inteiramente diferente" ${ }^{\prime \prime}$.

Em marubo, uma língua da família pano sobre a qual produzi diversos trabalhos, a partícula (iki), que costuma ser descrita como “cópula” pelos linguistas ${ }^{42}$, não é a única a surgir nos momentos em que vínculos extra-humanos são tematizados. Mesmo quando aparece, a mera análise linguística não seria suficiente para postular uma relação de identificação completa e genérica, como se não houvesse critérios suplementares de mediação usados para refletir sobre os vínculos. No trecho abaixo, a parteira e mestra dos desenhos kene Nazaré Rosãewa conversava comigo sobre o processo de "sucurização" de seu falecido esposo xamã, cujo corpo, que era chamado de João Pajé, servia de envoltório-casa para seu duplo sucuri, chamado de Kana Ina. Nesse momento da conversa ${ }^{43}$, ela cita a fala de seu falecido esposo sobre o devir-sucuri de seu duplo (vaká). Em seguida, retoma sua fala e produz uma reflexão geral sobre o processo:

\section{"Ea vẽchaya. \\ Ea vẽcha-ya. \\ IsABS sucuri-ATR \\ "Eu sucurizado.}

Naivo, neno na oĩ, neno tae pemaneki kene aya,

Na-ivo, neno na oĩ, neno tae pemane-ki kene aya,

DEMprox-GENR aqui DEMprox ver aqui pé costas-LOC desenho ter

Estes, olhe aqui, aqui nas costas do pé tem desenho

naivo kene aya, kene mashteya.

na-ivo kene aya, kene mashte-ya.

DEMprox-GENR desenho ter desenho terminar-PRF

tem estes desenhos, o desenho terminado.

4I Ibidem. É importante lembrar que as conclusões de Benveniste não implicam em uma reificação da língua, que serviria como critério e determinação para as formas de pensamento: "Nenhum tipo de língua pode por si mesmo e por si só favorecer ou impedir a atividade do espírito. O voo do pensamento liga-se muito mais estreitamente às capacidades dos homens, às condições gerais da cultura, à organização da sociedade que à natureza particular da língua”. Ibidem, p. 80.

42 Em shipibo-konibo, outra língua pano muito próxima do marubo, a cópula iki se baseia no verbo intransitivo ik-, além de também possuir força ilocucionária, de acordo com: VALENZUELA, Pilar. Transitivity in Shipibo-Konibo grammar. PhD Dissertation,University of Oregon, 2003, p. 257; 294.

43 A conversa está publicada integralmente em CESARINO, Pedro de Niemeyer, 20II, op. cit., p. 76 ss, mas sem a análise linguística aqui apresentada. Para o presente texto, revisei a tradução original na tentativa de enfatizar as variações relacionadas ao problema da cópula (ou de sua ausência). Legendas adotadas: Is - I⿳亠丷a pessoa singular; ABS - caso absolutivo; ASS - assertivo; ATR - atributivo condição permanente; CNS - consecutivo; COMP - comparativo; DEMprox - demonstrativo proximidade; DEMdist - demonstrativo distância; DIR - direcional; ENF - enfático; GENR - genérico; HAB - habitual; LE - língua especial; LOC - locativo; NEG negativo; PRF - aspecto perfectivo. 
Na mevi petxiri kene aya,

$\mathrm{Na}$ mevi petxi-ri kene aya,

DEMprox mão costas-DIR desenho ter

Nas costas das mãos tem desenho,

neno shotxinamã kene aya, neno shotxi-namã kene aya, aqui peito-LOC desenho ter aqui no peito tem desenho,

neno tamẽ pespã, neno kene aya ea, aská ea.” neno tamẽ pespã, neno kene aya ea, aská ea.” Aqui rostoLE aqui desenho ter Is assim Is aqui no rosto tem desenho, eu assim mesmo.”

[...]

Askásho vẽcha yorarvi,

Aská-sho vẽcha yora-rvi, assim-CNS sucuri gente-ENF

Por isso sucuri gente mesmo,

askásho wa yora ikitõki manã imismarvi.

aská-sho wa yora iki-tõ-iki manã i-miska-ma-rivi. assim-CNS DEMdist gente ser-COMP-ASS terra viver-HAB-NEG-ENF por isso aquele que é como gente não costuma viver na terra,

Wakã, waka niá.

Wakã, waka niá.

rioLOC rio viver

Está no rio, vive no rio.

Na tradução acima, optei por usar o verbo ser apenas na penúltima linha, em que a cópula iki ocorre em uma construção comparativa. Sem ser metafórica, ela pretende mostrar como os duplos dos corpos-sucuri são gente assim como os Marubo. Mas como, mais especificamente, se daria tal aproximação? Nas outras frases, a ausência de cópula não impede a reflexão sobre os vínculos gente-sucuri, que são dados pela ênfase na aproximação paratática dos termos "sucuri" e "gente" (vêcha yorarvi) e, mais importante, pela marcação do aspecto perfectivo na primeira frase, "Eu sucurizado" (Ea vêchaya). No mais, a narrativa evidencia o devir-sucuri através de uma dêixis sofisticada, que demonstra o processo de cobertura do corpo do duplo de João Pajé pelos padrões-sucuri, compostos por séries de losangos conectados em seus vértices (vêchã kene). O processo todo, portanto, é bem distinto de uma suposta fusão anímica genérica entre determinado homem e a serpente constritora, que poderia ser glosado por um etnógrafo desavisado como "não se trata de uma metáfora para relações sociais: ele é mesmo uma sucuri”. Ora, o corpo-carcaça (shaká) de João Pajé 
era efetivamente uma pessoa comum, mas seu duplo (vaká) é que se "sucurizava" a partir do acúmulo de diversos processos tais como a alteração estética, a troca de substâncias e o parentesco estabelecido com essas gentes outras. No fim, esse duplo não passa a adotar o aspecto da serpente, a se fundir ou se somar com o animal, mas sim a adquirir as qualidades corporais desses insólitos humanoides boídeos, que, entre outras características, têm os corpos elásticos e as juntas flexíveis associados a uma silhueta de tipo "humano" genérica44.

Vemos assim como toda uma série de critérios suplementares para as relações entre humano e não humano é postulada nesse devir-sucuri. Esses critérios versam sobre a extensão gradual de aspectos-sucuri sobre um corpo humanoide de base que, aos poucos, começa para si mesmo a se perceber desenhado, muito embora não necessariamente seja visto dessa forma por uma pessoa comum - no caso Nazaré Rosãewa, que era a destinatária das palavras de João Pajé acima citadas. De toda forma, o que se percebe em tal processo é algo distinto de uma fusão indistinta entre humano e não humano que se contraporia a um referente estável e neutro (o moderno) e mais uma espécie de bifurcação ou variação posicional da referência. É essa variação que garante a possibilidade do equívoco (no sentido dado por Viveiros de Castro ${ }^{45}$ ) e da decorrente multiplicação dos estatutos alternativos do humano.

Outro recurso comum para a visualização de tal variação através do discurso consiste em complexificar a construção enunciativa por uma série de construções em abismo, características de discursos e cantos xamânicos como os dos Marubo, dos Araweté e de tantos outros. Um indício de tal regime de enunciação pode ser visto no próprio trecho acima traduzido ${ }^{46}$, no qual a locutora cita as palavras de seu esposo, que fala sobre seu processo de sucurização. Casos análogos foram estudados recentemente por Heurich entre os Araweté. Dando continuidade à atenção pioneira ao problema da enunciação xamânica inaugurado por Viveiros de Castro (I986), Heurich ${ }^{47}$ mostra como palavras tais como inimigo, tatu, gente, entre outras, não possuem um referente fixo, pois são antes submetidas a uma variação posicional (ou de mundos, nos termos do autor) exprimida exatamente através da complexidade enunciativa. Vejamos, então, como isso se relaciona ao problema da virtualidade e da composição da pessoa em xamanismos como o marubo.

44 VIVEIROS DE CASTRO, Eduardo. A inconstância da alma selvagem, op. cit.

45 Idem, 2004.

46 Entre vários outros exemplos explorados com mais detalhes por mim em: CESARINO, Pedro de Niemeyer, 20II, op. cit.

47 HEURICH, Guilherme O. Música, morte e esquecimento na arte verbal araweté. Tese (Doutorado em Antropologia Social). Programa de Pós-Graduação em Antropologia Social, Museu Nacional /UFRJ, 20I5, p. I54-I55. 


\section{CONHECIMENTO E VIRTUALIDADE}

Os Marubo postulam uma bifurcação de todos os existentes entre os aspectos "corpo/ carcaça" e os aspectos "duplo". Dessa forma, a cena acima descrita implica em uma reflexão sobre dois processos paralelos: o da vida cotidiana de João Pajé-corpo e de sua duplicação em gente-sucuri. As séries paralelas bifurcadas, como se sabe, são uma constante entre outras ontologias xamanísticas ameríndias ${ }^{48}$. Fenômenos como o acima descrito não produzem exatamente, da parte daqueles que se engajam em rituais xamânicos, a crença na transformação do corpo do xamã em um animal. Nas sessões de pajelança que testemunhei, o corpo do xamã romeya permanece em seu aspecto normal, muito embora dê abrigo a uma multiplicidade de espíritos que ali chegam para cantar. Essa multiplicidade, que se faz notar através de seus cantos, danças, ensinamentos e curas, se transforma em um indício de uma miríade virtual de agentes humanoides bem mais vasta do que os poucos que ali decidem chegar.

A audiência sabe, assim, que o xamã alterado ali presente (ou seja, o seu invólucro corporal) não é exatamente o duplo de uma sucuri, por exemplo, mas sim aquele que transporta, isto é, que cita e que torna audível/visível um agente-sucuri outro. Esse agente outro não se funde ao corpo de determinado xamã em uma espécie de identidade paradoxal quimérica ${ }^{49}$, mas antes coabita o corpo-receptáculo a partir de sua posição virtual. A pessoa marubo é uma disposição fractal que prevê um embutimento da escala espacial e arquitetônica externa (composta pela maloca em que estão as pessoas) em uma escala interna (a maloca em que vivem os duplos da pessoa) $)^{50}$. Longe de ser metafórica, essa disposição do corpo como espaço arquitetônico escalar é também desenvolvida ao menos pelos Yanomami ${ }^{51}$. Ela termina por demandar uma série de critérios de mediação e de aderência da audiência com relação à identidade ontológica complexa que ali se apresenta e que costumamos individualizar em nossa escrita etnográfica como "xamã" ou "pajé".

Um desenho feito certa vez por Benedito Keninawa, professor e aprendiz de pajé marubo, revela bem o ponto. O desenho é uma espécie de esquema didático endereçado a mim, na tentativa de explicar o que seria afinal das contas um pajé. Ele segue acompanhado de minha tradução das legendas, escritas em marubo pelo autor no original.

\footnotetext{
48 Lima foi uma das primeiras a formular o fenômeno em termos similares para os Juruna. LIMA, Tania Stolze.

O dois e seu múltiplo: reflexões sobre o perspectivismo em uma cosmologia tupi. Mana, v. 2, n. 2, I996, p. 2I-47.

49 SEVERI, Carlo. Le principe de la chimère. Paris: Éditions Rue d'Ulm/ Musée du Quai Branly, 2007.

50 CESARINO, Pedro de Niemeyer, 20II, op. cit.

5 I Cf.: ALBERT, Bruce; KOPENAWA, Davi, op. cit.
} 


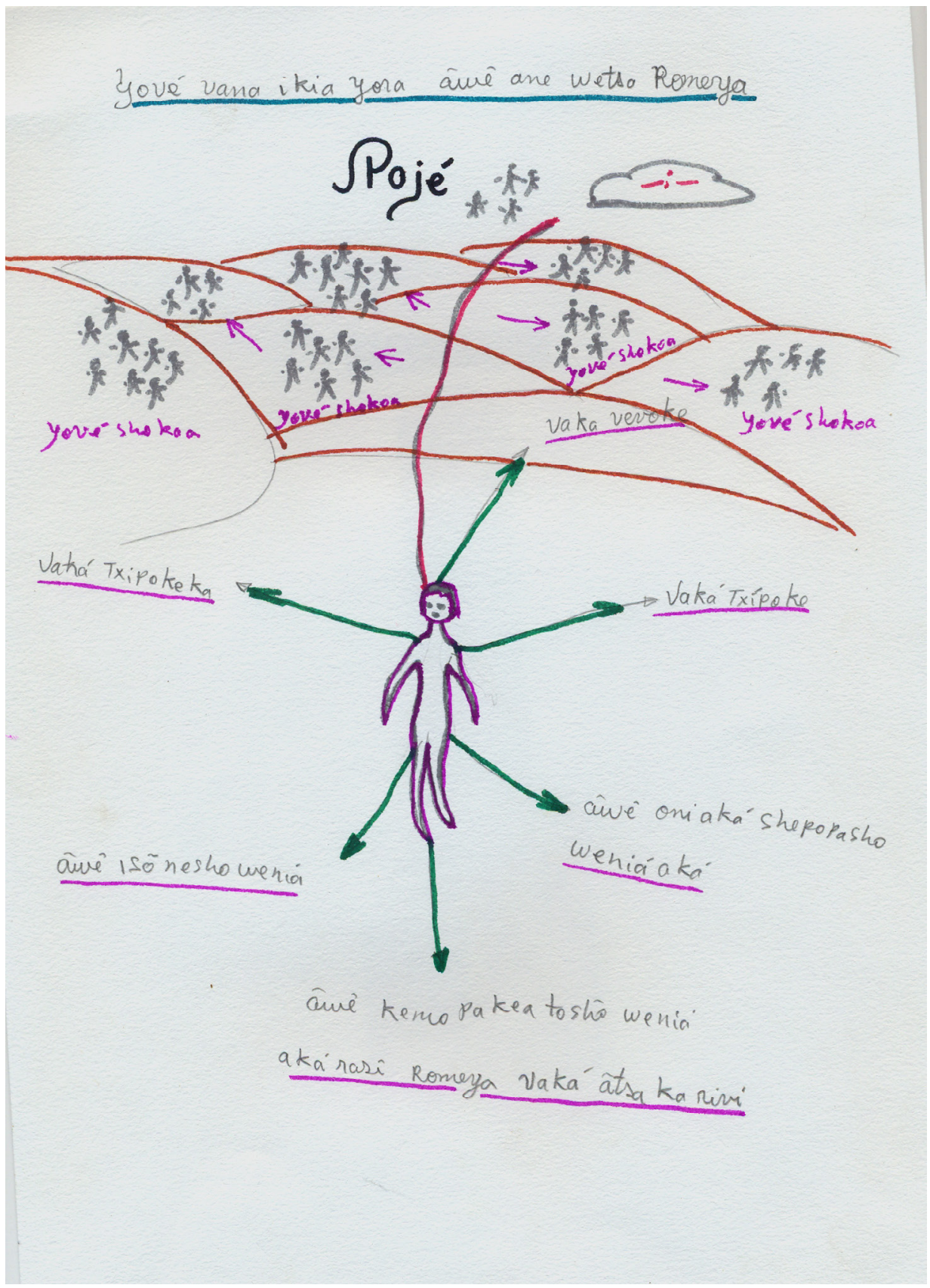

Figura I - Benedito Dionísio Marubo Keninawa. "Pajé”, 2005 


\section{TRADUÇÃO DAS LEGENDAS}

[centro superior]

Yove vana ikia yora awen ane wetsa Romeya

"Pessoa citadora das falas dos espíritos cujo outro nome é pajé/Romeya"

[faixa superior intermediária/montanhas]

Yové shokoa,

"espíritos reunidos" (diversas vezes)

[seta superior]

vaká vevoke,

"duplo mais velho"

[seta esquerda]

vaká txipokeka,

"duplo mais novo"

[seta direita]

vaká txipoke,

"duplo do meio"

[seta inferior esquerda]

awen isõnesho wenía,

"[duplo] surgido de sua urina"

[seta inferior direita]

awen oni aká shepopasho wenía aká,

"[duplo] surgido do resto de sua ayahuasca"

[seta inferior]

awen kemo pakeatõsho wenía,

"[duplo] surgido de sua saliva”

[faixa inferior]

akárasin romeya vaká ãtsarivi,

"estes são os diversos duplos do pajé"

A imagem mostra a multiplicidade de duplos de que se constitui "pajé", que, aqui como em outros mundos ameríndios, é uma posição provisória e instável, de saúde corporal frágil e inconstante, nem sempre apta a conter a dispersão potencial de seus aspectos. O desenho se divide, ainda, em dois eixos fundamentais, indicados pela direção superior ou inferior das setas. A tríade de duplos/setas superiores (que, na verdade, se completa por uma quarta linha não acabada, provavelmente elaborada 
para esquematizar o duplo do olho, verõ yochin) é aquela dos irmãos, caracterizada por um vínculo privilegiado com a multiplicidade dos agentes que costumamos chamar de "espíritos". Esse vínculo se estabelece enquanto dura o corpo/posição do romeya, que congrega tais multiplicidades durante sua existência, mas, também, depois de sua morte ou desintegração, na qual os duplos passarão a viver com os espíritos aí distribuídos em suas colinas (matô), ou seja, em suas moradas infinitas. O eixo inferior, por sua vez, indicaria, no caso de uma pessoa ordinária, os duplos que não têm destino privilegiado e que permanecem aqui nesta terra sob a forma de espectros desgrenhados e desgarrados. À exceção, talvez, do duplo da urina, o romeya possui outros tantos duplos derivados de suas extensões "enteógenas" (a ayahuasca, o rapé e a saliva desprendida pelo consumo de tais extensões) que são também multiplicidades. Quando um pajé cospe no chão ou deixa derrubar a sua ayahuasca ou exala uma nuvem de pequenas partículas de rapé, ele prolifera uma multiplicidade de duplos que são também espécies de irmãos mais velhos.

Para o xamanismo marubo, assim como para o yanomami descrito por Davi Kopenawa em A queda do céu e tantos outros, o que designamos por "espírito" se refere, se vale seguir a sugestão precisa de Viveiros de Castro ${ }^{52}$, a uma multiplicidade simultaneamente anterior e contemporânea à existência dos atuais humanos. Poderíamos dizer então, pelos termos de Manuel de Landa, que eles são, enquanto multiplicidade virtual, os "componentes vitais do mundo objetivo" ${ }^{33}$, sem os quais este mundo não poderia existir. O conhecimento humano, tal como concebido por xamanismos como o dos Marubo, pode ser compreendido como uma tentativa de devir tal multiplicidade via a transformação dos corpos atualmente existentes. Com isso, a possibilidade de uma aliança com tais agentes se tornaria possível e daria margem para um futuro póstumo melhor.

$\mathrm{O}$ uso da noção de virtual, realizado por mim em trabalhos anteriores, foi recentemente comentado por Pierre Déléage. $O$ autor, especialista também nas artes verbais e no xamanismo de um povo falante de língua pano, concorda com meu uso da noção de virtual para tratar das configurações xamanísticas, exceto por um ponto significativo. Déléage ${ }^{54}$ acha que o virtual é uma propriedade que só pode existir depois ou a partir dos processos de aprendizagem, ao passo que, de meu ponto de vista, essa dimensão do real seria independente de tais processos. Déléage elabora a questão ao tratar, em um livro recente, de meus dados e estudos sobre a relação entre desenhos e cantos xamânicos ${ }^{5}$. Ele se refere ao meu estudo de um esquema triádico (baseado nas unidades surgimento, trajeto e estabelecimento) que serve de base para a composição de cantos que versam sobre a origem de espíritos e outros agentes, bem como sobre as possibilidades de neutralizá-los através da ação ritual. Esse esquema de base (surgimento/trajeto/estabelecimento) estaria presente não apenas na estrutura de fórmulas verbais que compõem os cantos, mas, também, nos desenhos que alguns

52 VIVEIROS DE CASTRO, Eduardo. A floresta de cristal: notas sobre a ontologia dos espíritos amazônicos. Cadernos de Campo, v. I5, n. I4-I5, 2006, p. 3I9-39.

53 DE LANDA, Manuel. (2002). Intensive science and virtual philosophy. Londres: Bloomsbury, 20I2, p. 24.

54 DÉLÉAGE, Pierre. Lettres mortes. Essai d’anthropologie inversée. Paris: Fayard, 20I7, p. I45.

55 CESARINO, Pedro de Niemeyer, 20II, op.cit.; 20I3, op. cit. 
xamãs marubo realizaram a meu pedido e, ainda, nas coreografias de diversos dos festivais marubo.

O recurso à noção de virtual não é novo na antropologia ou na etnologia americanista. Foi usado antes, por exemplo, por Lévi-Strauss ${ }^{56}$ ao definir o mito como um objeto virtual, cujas propriedades estruturais se pensam entre si e a despeito do sujeito mas, também, por Viveiros de Castro em seus estudos sobre as relações de afinidade na Amazônia. Viveiros de Castro pôde, a partir daí, pensar a relação entre uma referência temporal primeira e outra atual, através da noção de virtual57. Mas por quais razões eu teria empregado tal noção e por que Déléage discorda da maneira pela qual eu a compreendo? Viveiros de Castro estava preocupado em mobilizar a noção de virtual para explicar o problema da afinidade na Amazônia e, através daí, da relação entre os tempos míticos e o tempo atual. Para mim, o conceito não apenas traduzia de maneira muito produtiva as configurações multiposicionais da cosmologia marubo como, também, os processos de aquisição e de transmissão do conhecimento.

Ao tratar dos conceitos deleuzianos, o filósofo Manuel de Landa explica que as multiplicidades demandam um estatuto ontológico para que possam ser compreendidas. Esse estatuto ontológico deve ser outro que o derivado da relação entre real e irreal, pois as multiplicidades devem ser mais bem compreendidas através da relação virtual-atual. O virtual, portanto, é também real; ele se constitui, como dizíamos, como um "componente vital do mundo objetivo"58. Deleuze e Guattari, por sua vez, definem a multiplicidade "não pelos elementos que a compõem em extensão, nem pelos caracteres que a compõem em compreensão, mas pelas linhas e dimensões que ela comporta em 'intensidade'. Se as dimensões são alteradas, se são subtraídas ou somadas, muda-se de multiplicidade" ${ }^{59}$. As consequências de tal pressuposto para a noção de devir são conhecidas: "Essas multiplicidades de termos heterogêneos, que cofuncionam por contágio, entram em certos agenciamentos, e é assim que o homem opera os seus devires-animais"6o.

O que costumo chamar de "xamanismo marubo" é, assim, uma configuração cosmológica que pode ser traduzida a partir de tais conceitos, ou seja, uma multiplicidade intensiva de posições que se atualizam neste ou naquele estado ou singularidade possível de tipo "porco do mato", "humano" ou "sucuri”. Em outros termos, a estabilização provisória dos corpos, que se tornam então tangíveis, visíveis e comunicáveis para a experiência ordinária, pressupõe uma fuga potencialmente infinitesimal, na qual essas mesmas posições estabilizadas se agenciariam com outras complexidades possíveis. Poder-se-ia dizer então que os agentes potencialmente postos em relação derivam de um plano virtual de agenciamentos para ocupar esta ou aquela posição provisória. O tal do “xamanismo” seria, então, uma estratégia

56 LÉVI-STRAUSS, Claude. Le cru et le cuit. Paris: Plon, I964, p. 20, 25.

57 VIVEIROS DE CASTRO, Eduardo, 2002, op. cit., p. I24.

58 DE LANDA, Manuel, op. cit., p. 24.

59 DELEUZE, Gilles; GUATTARI, Félix, op. cit., p. 299.

60 Ibidem, p. 296 
necessária para controlar e mediar os riscos derivados de tais passagens entre o virtual e o atual.

O campo virtual de que se compõe o conhecimento de cantos e coreografias, portanto, não poderia de forma alguma ser posterior ao aprendizado dos mesmos, pois ele não é uma propriedade ou um efeito do Sujeito. Uma coisa, portanto, seria identificar uma posição possível (tal como aquela ocupada pelo corpo do desenho de Benedito) como um "sujeito" capaz de produzir enunciados, de ocupar uma perspectiva. Outra implicaria em pressupor o Sujeito como substância ou entidade metafísica, que seria o responsável ou depositário último dos processos de produção e de aquisição de conhecimento. Esta segunda alternativa é incompatível com a maneira pela qual a configuração cosmológica marubo me foi explicada. Ora, mas ela também é incompatível com os pressupostos modernos sobre a produção de conhecimento, para os quais matrizes virtuais só poderiam ser compreendidas como uma espécie de arte da memória dependentes de algum foro interno, de algum processo cognitivo disparado inicialmente por um Sujeito que coincide com o próprio Homem, situado no centro de sua ontologia. A reflexão etnográfica deveria, portanto, mediar tal diferença de pressupostos a fim de não tomar uns pelos outros.

\section{CONSIDERAÇõES FINAIS}

Como relacionar o problema da virtualidade acima tratado com a questão da cópula predicativa e das estratégias linguísticas alternativas para a produção e reflexão sobre os vínculos extra-humanos? Em casos como o marubo, a presença de uma identidade e de um enunciador complexo como o do xamã serve como indicação de um plano virtual, como se aquele corpo ali visível fosse não uma fusão paradoxal de predicados, mas uma remissão ao jogo das posições potenciais e atuais ${ }^{6 \mathrm{I}}$. Essa remissão é permeada por uma dialogicidade complexa, notável nas longas sessões xamânicas durante as quais homens e mulheres instruídas nos assuntos especiais entretêm suas especulações sobre a identidade e os propósitos de determinado conjunto de visitantes extra-humanos. Essas especulações se dão a partir de critérios de mediação e de tradução: nesse momento, em qual lugar estará determinado aspecto atrelado ao xamã-corpo? Quem será o recém-chegado, que transmite esse canto? Entre os Marubo, corpos doentes (sejam eles os de xamãs ou de pessoas comuns) também são submetidos ao mesmo tipo de escrutínio, através do qual um conjunto de xamãs rezadores (os kenchintxo) investiga os agentes que, no plano virtual, sequestram, seduzem ou molestam o duplo da pessoa. De toda forma, não é sobre esse corpo visível que incide a sobreposição de identidades e a confusão dos vínculos humano/ extra-humano, mas sim sobre o pano de fundo multiposicional. Tudo se passa, assim, como se o corpo doente e/ou alterado fosse antes um mediador capaz de apontar não para a instabilidade do ser ou do ente - princípios conceituais incompatíveis com os casos em pauta - mas sim para existentes marcados por uma variação posicional virtual.

Assim, a pressuposição da fusão de identidades sobre a qual falávamos acima

6I CESARINO, Pedro de Niemeyer. Eventos ou textos? A pessoa múltipla e o problema da tradução das artes verbais amazônicas. In: DAHER, A. (Org.). Oral por escrito. Chapecó: Argos/Ed. da UFRJ. No prelo. 
implica em imaginar que não exista nenhuma forma alternativa de mediação entre existentes ou, em outros termos, que nenhuma forma de "consciência crítica"62 sobre identidades complexas esteja em jogo nas relações xamanísticas tais como as aqui comentadas. Tudo se passaria, portanto, como se a presunção de identidade ou de personitude de fenômenos tais como montanhas, petróglifos, efígies e corpos de xamãs fosse imediata, baseada em um problema de identidade ontológica nem sempre traduzível de maneira direta nas línguas ameríndias. O contrário disso, entretanto, não deve ser a remissão aos ameríndios de uma racionalidade prática universal avessa a ontologias exóticas produzidas por antropólogos, se vale recordar aqui os termos da velha disputa entre Sahlins e Obeyesekere ${ }^{63}$. Tampouco implicaria em pressupor essa adesão a identidades complexas como a de xamãs ao mecanismo subjetivo da crença e ao efeito perlocucionário da performance, como quer Severi ${ }^{6}$.

Uma outra estratégia se faz necessária. Ela parece estar atrelada à associação profunda entre tradução e proliferação conceitual que, como vimos, é fundamental para que linguagens analíticas das mais diversas se contaminem e se reinventem, ao invés de permanecerem colonizadas por apenas um estilo provinciano de pensar. De fato, uma análise mais atenta do problema da tradução pode oferecer elementos importantes para compreender a maneira como os vínculos são elaborados ou como determinadas questões ontológicas são colocadas por regimes de conhecimento como os ameríndios. Tais problemas certamente não são os únicos a oferecer elementos para os modos de se conceber os limites do humano, muito embora certamente não possam ser desprezados por quem se interessa em explorar o alcance imaginativo da etnografia.

\section{SOBRE O AUTOR}

PEDRO DE NIEMEYER CESARINO é professor do Departamento de Antropologia da Faculdade de Filosofia, Letras e Ciências Humanas da Universidade de São Paulo (FFLCH/USP), nas áreas de pesquisa Antropologia das Formas Expressivas e Etnologia Indígena, e pesquisador do Centro de Estudos Ameríndios (CEstA/USP).

E-mail: pncesarino@usp.br

62 LATOUR, Bruno. O que é iconoclash? Ou, há um mundo além das guerras de imagem?. Horizontes Antropológicos, v. I4, n. 29, 2008, p. III-I50.

63 BOROFSKY, Robert. Cook, Lono, Obeyesekere and Sahlins: CA* Forum on theory in anthropology. Current Anthropology, v. 38, n. 2, I997, p. 255-282.

64 SEVERI, Carlo. Memory, reflexivity and belief - reflections on the ritual use of language. Social Anthropology, v. Io, n. I, 2002, p. 23-40. p. 38. 


\section{REFERÊNCIAS BIBLIOGRÁFICAS}

ALBERT, Bruce; KOPENAWA, Davi. La chute du ciel. Paris: Plon, 2010.

ALMEIDA, Mauro William Barbosa de. Caipora e outros conflitos ontológicos. R@u, v. 5, n. I, 20I4, p. 7-28. BENVENISTE, Émile. Problemas de linguística geral I. Campinas: Pontes/Editora da Unicamp, I995.

BOROFSKY, Robert. Cook, Lono, Obeyesekere and Sahlins: CA* Forum on theory in anthropology. Current Anthropology, v. 38, n. 2, I997, p. 255-282.

LA CADENA, Marisol de. Earth beings - ecologies of practice across Andean worlds. Durham \& London: Duke University Press, 2015.

CADOGAN, León. (I946). Ayvu rapyta - textos míticos de los Mbyá-Guaraní del Guairá. Asunción: Ceaduc-Cepag, I997.

CASSIN, Barbara. Parménide - sur la nature ou sur l'étant. La langue de l'être. Paris: Seuil, I998.

CESARINO, Pedro de Niemeyer. Oniska - poética do xamanismo na Amazônia. São Paulo: Perspectiva/ Fapesp, 20II.

. Cartografias do cosmos: conhecimento, iconografia e artes verbais entre os Marubo. Mana, v. I9, n. 3, 2013, p. 437-47I. (Org.). Quando a terra deixou de falar - cantos da mitologia marubo. São Paulo: Ed. 34, 2013.

. A voz falível - ensaio sobre as formações ameríndias de mundos. Literatura e Sociedade, n. I9, 2014, p. 76-99.

. Eventos ou textos? A pessoa múltipla e o problema da tradução das artes verbais amazônicas. In: DAHER, A. (Org.). Oral por escrito. Chapecó: Argos/Ed da UFRJ. No prelo.

CLASTRES, Pierre. (I974). Le grand parler. Paris: Seuil.

DE LANDA, Manuel. (2002). Intensive science and virtual philosophy. Londres: Bloomsbury, 2012.

DÉLÉAGE, Pierre. Le chant de l'anaconda: l'apprentissage du chamanisme chez les Sharanahua (Amazonie occidentale). Nanterre: Société d'Ethnologie, 2009.

. Lettres mortes. Essai d'anthropologie inversée. Paris, Fayard, 2017.

DELEUZE, Gilles; GUATTARI, Félix. Mille plateaux. Paris: Les Éditions de Minuit, I980.

FREEDBERG, David. The power of images. Chicago \& Londres: The University of Chicago Press, I989.

HANKS, William; SEVERI, Carlo. Translating worlds. The epistemological space of translation. Hau Journal of Ethnographic Theory, v. 4, n. 2, 20I4, p. I-I6.

HEURICH, Guilherme O. Música, morte e esquecimento na arte verbal araweté. Tese (Doutorado em Antropologia Social). Programa de Pós-Graduação em Antropologia Social, Museu Nacional /UFRJ, 2015.

HOLBRAAD, Martin; PEDERSEN, Morten Axel. The ontological turn - an anthropological exposition. Cambridge: Cambridge University Press, 2017.

HUGH-JONES, Stephen. Escrita nas pedras, escrita no papel. In: FAUSTO, C.; SEVERI, C. Palavras em imagens - escritas, corpos e memórias. Marseille: Open Edition Press, 20I5, p. 57-85.

LATOUR, Bruno. O que é iconoclash? Ou, há um mundo além das guerras de imagem?. Horizontes Antropológicos, v. I4, n. 29, 2008, p. III-I50.

LÉVI-STRAUSS, Claude. Le cru et le cuit. Paris: Plon, I964.

LIMA, Tania Stolze. O dois e seu múltiplo: reflexões sobre o perspectivismo em uma cosmologia tupi. Mana, v. 2, n. 2, I996, p. 2I-47.

LLOYD, G. E. R. The ambitions of curiosity. Cambridge: Cambridge University Press, 2002.

MANIGLIER, Patrice. Manifesto para um comparatismo superior em filosofia. Tradução Richer de Souza e Melissa Mora Mello. Veritas - revista de Filosofia da PUCRS, v. 58, n. 2, 20I3, p. 227-27I. Disponível 
em: 〈revistaseletronicas.pucrs.br/ojs/index.php/veritas/article/view/I6645/I09I4〉. Acesso em: 22 jan. 2018.

SEVERI, Carlo. Memory, reflexivity and belief - reflections on the ritual use of language. Social Anthropology, v. IO, n. I, 2002, p. 23-40.

. Le principe de la chimère. Paris: Éditions Rue d’Ulm/ Musée du Quai Branly, 2007.

. Transmutating beings - a proposal for an anthropology of thought. Hau, v. 4, n. 2, 20I4, p. 4I-7I.

STRATHERN, Marilyn. The gender of the gift. Berkeley: The University of California Press, I988. . Partial connections. Oxford: Altamira Press, 2005.

VALENZUELA, Pilar. Transitivity in Shipibo-Konibo grammar. PhD Dissertation, University of Oregon, 2003.

VIVEIROS DE CASTRO, Eduardo. A inconstância da alma selvagem. São Paulo: Cosac Naify, 2002. . O nativo relativo. Mana, v. 8, n. I, 2002, p. Ir3-I48.

. Perspectival anthropology and the method of controlled equivocation. Tipití, v. 2, n. I, 2004, p. 3-23.

. A floresta de cristal: notas sobre a ontologia dos espíritos amazônicos. Cadernos de Campo, v. I5,

n. I4-I5, 2006, p. 3I9-39. 